\title{
Anti-angiogenic and antitumor activities of Huaier aqueous extract
}

\author{
XIAOLONG WANG, NING ZHANG, QIANG HUO and QIFENG YANG
}

Department of Breast Surgery, Qilu Hospital, Shandong Univeristy School of Medicine, Jinan, Shandong 250012, P.R. China

Received June 12, 2012; Accepted July 13, 2012

DOI: 10.3892/or.2012.1961

\begin{abstract}
Traditional Chinese medicine, a rich source of potent cancer chemopreventive agents, is attracting increasing attention worldwide. Recently, the anticancer activity of Trametes robiniophila Murr. (Huaier) has been widely investigated. However, the mechanisms are not yet fully understood. This study aimed to elucidate the inhibitory effect of Huaier extract on angiogenesis and tumor growth. Incubation with Huaier extract inhibited the proliferation of human umbilical vein endothelial cells (HUVECs) and mouse mammary tumor cells (4T1). In addition, treatment with Huaier extract decreased the motility and tube formation of HUVECs in a dose-dependent manner in vitro. As determined by western blot analysis, Huaier extract dose-dependently decreased the levels of phosphorylated extracellular signal-regulated kinase (ERK), transcription factor p65, c-Jun N-terminal kinase (JNK), signal transducer and activator of transcription 3 (STAT3) and the expression of vascular endothelial growth factor (VEGF). In ex vivo experiments, new vessel growth was suppressed as shown by chick embryo chorioallantoic membrane (CAM) and rat aortic ring assays in the presence of Huaier extract. To further evaluate the inhibitory effect, 4T1 cells were injected subcutaneously into BALB/c mice. The administration of Huaier extract suppressed tumor volume, decreased microvessel density and induced apoptosis. These data suggest that Huaier extract may serve as a potent anti-angiogenic and antitumor agent.
\end{abstract}

\section{Introduction}

Cancer, a multi-step and systematic disease, is a leading cause of mortality worldwide. In 2008, 7.6 million deaths due to cancer were recorded (approximately 13\% of the total number of deaths) (1). As one of the main types of cancer, breast cancer accounted for 458,000 deaths in 2008 (1). There were almost 230,480 new cases of invasive breast cancer and 39,520 breast cancer deaths among women in the US 2011 (2). In developing

Correspondence to: Professor Qifeng Yang, Department of Breast Surgery, Qilu Hospital, Shandong University School of Medicine, Wenhua Xi Road 44, Jinan, Shandong 250012, P.R. China

E-mail: qifengy@gmail.com

Key words: Huaier, angiogenesis, tumor, 4T1, human umbilical vein endothelial cell countries, breast cancer occupies approximately half of the total number of breast cancer cases worldwide and $60 \%$ of deaths, and is the leading cause of cancer mortality among women in this area (3). In China, the incidence of breast cancer increased rapidly from 126,227 cases in 2002 (4) to 169,452 in 2008 (5). However, currently available chemotherapy treatments provide little benefit, combined with serious side-effects and dose-limiting toxicities (6). Therefore, agents which can interfere with the essential steps of cancer development, such as angiogenesis, are being increasingly used in the treatment of human cancer $(7,8)$.

Angiogenesis is a complex process, referring to the formation of new blood vessels from pre-existing ones (9). During angiogenesis, several steps are involved: degradation of the extracellular matrix, migration, proliferation, sprouting, elongation and tube formation of endothelial cells (10). It is well known that physiological angiogenesis has a great contribution to embryonic development, wound healing and tissue regeneration (11-13), and it is tightly controlled by the balance between the pro-angiogenic factors, such as vascular endothelial cell growth factor (VEGF) and anti-angiogenic factors, such as endostatin. Forming new blood vessels is an essential step in tumor development (14-17). Without blood supply, the tumor volume will not exceed $1-2 \mathrm{~mm}^{3}$ (18). Tumor development can only continue with the formation of new blood vessels (19). Therefore, anti-angiogenesis is a promising strategy for cancer treatment.

Since angiostatin and endostatin were recognized as endogenous anti-angiogenic factors, a number of phytochemicals, such as Salvia officinalis (20), cinnamon extract (21), and koetjapic acid from Sandoricum koetjaoe Merr. (22), have been proven to possess anti-angiogenesis activities. Trametes robiniophila Murr. (Huaier extract) a traditional Chinese medicine (TCM), has been widely used in China for many years. Previous studies have reported that Huaier extract inhibits the growth of hepatocellular carcinoma cells $(23,24)$, and our previous study showed that Huaier aqueous extract inhibited the proliferation of breast cancer cells by inducing apoptosis (25). Although the antitumor activity of Huaier extract has been revealed, the exact underlying mechanisms remain largely unknown. In the present study, we evaluated the anti-angiogenic effect of Huaier extract, in combination with its antitumor effects.

\section{Materials and methods}

Reagents. The human umbilical vein endothelial cell line (HUVEC) and mouse mammary tumor cell line, 4T1, were 
purchased from the American Type Culture Collection (ATCC, Manassas, VA, USA), and were routinely cultured in DMEM medium (Gibco-BRL, Rockville, IN, USA) containing 10\% FBS (Haoyang Biological Manufacturer Co., Ltd., Tianjin, China), $100 \mathrm{U} / \mathrm{ml}$ penicillin and $100 \mu \mathrm{g} / \mathrm{ml}$ streptomycin in 5\% $\mathrm{CO}_{2}$ at $37^{\circ} \mathrm{C}$. Anti-p21, anti-extracellular signal-regulated kinase (ERK), anti-phosphorylated (p)-ERK, anti-c-Jun N-terminal kinase (JNK), anti-p-JNK, anti-p65, anti-p-p65, anti-signal transducer and activator of transcription 3 (STAT3) and anti-pSTAT3 (ser727) antibodies were obtained from Cell Signaling Technology, (Beverly, MA, USA). Anti-VEGF antibody was provided by Abcam, (Cambridge, MA, USA). Anti- $\beta$-actin (1:5000) antibody was obtained from Sigma-Aldrich (St. Louis, MO, USA). Anti-mouse and rabbit IgG horseradish peroxidase (HRP) antibodies (1:5000) was from ZhongShan Goldenbridge Biotechnology Co., Ltd. (Beijing, China). The pro-lighting HRP agent for western blot analysis was supplied by Tiangen Biotech Co., Ltd., (Beijing, China).

Preparation of Huaier aqueous extract. Electuary ointment of Huaier extract was kindly provided by Gaitianli Medicine Co., Ltd. (Jiangsu, China). The electuary ointment $(2 \mathrm{~g})$ was soaked in $20 \mathrm{ml}$ of DMEM. The solid residue of the above dissolved herbs was filtered and discarded through a $0.22-\mu \mathrm{m}$ filter. The final $100 \mathrm{mg} / \mathrm{ml}$ stock solution was kept at $-20^{\circ} \mathrm{C}$ for long storage.

Effect of Huaier extract on cell morphology. HUVECs were seeded in a 24 -well plate. After $12 \mathrm{~h}$, the HUVECs were exposed to various concentrations of Huaier extract for an additional $24 \mathrm{~h}$. Finally, the morphological changes caused by Huaier extract were observed under an Olympus light microscope and photomicrographs were taken with an Olympus digital camera (Olympus, Tokyo, Japan).

3-(4,5-Dimethylthiazol-2-yl)-2,5-diphenyltetrazolium bromide (MTT) assay. MTT assay was performed to measure the viability of the HUVECs and 4T1 cells after treatment with Huaier extract. In brief, the HUVECs $\left(10^{3}\right.$ cells/well) and 4T1 cells (700 cells/well) were seeded in cultured medium in 96-well plates and incubated in $5 \% \mathrm{CO}_{2}$ at $37^{\circ} \mathrm{C}$. After $12 \mathrm{~h}$, the medium in each well was replaced with the vehicle or different concentrations $(2,4$ and $8 \mathrm{mg} / \mathrm{ml})$ of Huaier extract and incubated for another 48 or $72 \mathrm{~h}$. Subsequently, $20 \mu \mathrm{l}$ of MTT $(5 \mathrm{mg} / \mathrm{ml}$ in PBS) were added into each well. After $4 \mathrm{~h}$ of incubation at $37^{\circ} \mathrm{C}$, the supernatants were aspirated carefully and $100 \mu 1$ of dimethyl sulfoxide (DMSO) were added to each well. Absorbance values at $490 \mathrm{~nm}$ were determined by the Microplate Reader (Bio-Rad, Hercules, CA, USA).

Cell cycle analysis. After $24 \mathrm{~h}$ of starvation in serum-free medium at $37^{\circ} \mathrm{C}$, the HUVECs were treated with various concentrations of Huaier extract or complete medium as the negative control. After $24 \mathrm{~h}$, the treated cells were harvested, washed with $1 \mathrm{X}$ cold PBS and fixed with $70 \%$ ice-cold ethanol overnight. After the ethanol was removed by centrifugation at $1,200 \mathrm{xg}$ for $1 \mathrm{~min}$, the fixed cells were washed with PBS twice. The pellets were then resuspended with $1 \mathrm{ml}$ of DNA staining solution (MultiSciences Biotech Co., Ltd.). After incubation for $30 \mathrm{~min}$ at room temperature in the dark, cells were analyzed in the presence of the dye by FACScan flow cytometry (BectonDickinson, Franklin Lakes, NJ, USA) and the data were analyzed by ModFitLT V2.0 software (Becton-Dickinson).

Propidium iodide (PI)-Annexin-V staining analysis. The BD Pharmingen $^{\mathrm{TM}}$ PE Annexin V Apoptosis Detection Kit (BD Biosciences, Franklin Lakes, NJ, USA) was used to detect the proportion of apoptotic cells, according to the instructions of the manufacturer. Briefly, after treatment with various concentrations of Huaier extract for the indicated times, the HUVECs were harvested and washed with PBS twice. The cells $\left(1 \times 10^{5}\right)$ were then resuspended in $100 \mu 1$ of binding buffer, followed by adding $5 \mu \mathrm{l}$ Annexin V-FITC and $5 \mu \mathrm{l}$ PI. After incubation for $15 \mathrm{~min}$ in the dark, another $400 \mu \mathrm{l}$ of binding buffer were added before the cells were analyzed by FACScan flow cytometry.

In vitro scratch assay. Scratch assay was applied to determine cell mortality caused by Huaier extract. This assay was performed using a standard method (26) with some modifications. Briefly, 2.5x $10^{4}$ HUVECs were seeded on a 12-well plate in complete medium overnight to obtain a full confluent monolayer. After $24 \mathrm{~h}$ of starvation, a $20-\mu \mathrm{l}$ pipette tip was used to create a straight cell-free wound. Each well was washed twice with PBS to remove debris. The cells were then cultured in serum-free medium in the absence or presence of various concentrations of Huaier extract. The distances between the 2 edges of the scratch were analyzed quantitatively.

Cell migration assay. In vitro cell migration assay was performed using the Transwell system (24-wells, $8-\mu \mathrm{m}$ pore size with polycarbonate membrane; Corning Costar, Lowell, MA, USA). Cells were starved in serum-free medium for $24 \mathrm{~h}$ at $37^{\circ} \mathrm{C}$. The HUVECs were then harvested and resuspended in various concentrations of Huaier extract diluted in serum-free medium. The conditional medium from the NIH3T3 fibroblasts and the complete medium were then mixed (v/v 1:1). Subsequently, $1 \mathrm{ml}$ of the mixture was added to the lower well of each chamber, and $100 \mu \mathrm{l}$ of cell solutions containing $1 \times 10^{4}$ HUVECs were added to the upper wells. After treatment for $24 \mathrm{~h}$, the cells attached to the lower surface were fixed with methanol and stained with $0.2 \%$ Giemsa. The successfully migrated cells were counted on 5 random fields using an Olympus light microscope.

Tube formation assay. The ability of the HUVECs to form network structures was tested on Matrigel basement membrane matrix (BD Biosciences, San Jose, CA, USA). Firstly, $50 \mu 1$ of Matrigel were plated per well on 96-well plates and allowed to polymerize at $37^{\circ} \mathrm{C}$ for $30 \mathrm{~min}$. Subsequently, $100 \mu \mathrm{l}$ of HUVECs suspended in complete medium at a density of $1 \times 10^{5} /$ $\mathrm{ml}$ were added to each well in the absence or presence of Huaier extract. After $9 \mathrm{~h}$, tube-like structures were photographed with an Olympus digital camera.

Chick embryo chorioallantoic membrane (CAM) assay. CAM assay was performed as described previously (27) with small modifications. Briefly, 40 fertilized chicken eggs were incubated at $37^{\circ} \mathrm{C}$ at constant humidity and randomly divided into 4 groups. On the 9th day of incubation, a square window $\left(1 \times 1 \mathrm{~cm}^{2}\right)$ was opened in the shell. The following day, filter discs loaded with $20 \mu \mathrm{l}$ complete medium or various concentrations of Huaier 
extract were placed on the top of the growing CAMs under sterile conditions. Afterwards, the window was sealed with sterilized surgical tape and the eggs were returned to the incubator. After $24 \mathrm{~h}$ of incubation, the CAMs were photographed using an Olympus Live View Digital SLR camera.

Rat aortic ring assay. Angiogenesis ex vivo was also studied by rat aortic ring assay (28). Briefly, a 48-well plate was first covered with Matrigel and incubated for $30 \mathrm{~min}$ at $37^{\circ} \mathrm{C}$. Subsequently, 2-month old BALB/c mice were sacrificed by cervical dislocation, and the thoracic aortas were dissected and cut into 1-2-mm long sections. Afterwards, aortic rings were placed into wells pre-coated with Matrigel, and then covered with another layer of Matrigel. After 30 min of polymerization, DMEM supplemented with $20 \%$ FBS was added into each well. The following day, the supernatants were replaced with medium in the absence or presence of various concentrations of Huaier extract. On day 6 , the fields covered by the sprouting from the aortic rings were measured by an Olympus digital camera.

Western blot analysis. In brief, the HUVECs were allowed to grow to $60-70 \%$ confluence in $25 \mathrm{~cm}^{2}$ cell culture flasks, and then incubated with gradient concentrations of Huaier extract at $37^{\circ} \mathrm{C}$ under $5 \% \mathrm{CO}_{2}$. After $2 \mathrm{~h}$ of treatment, the cells were harvested, and the proteins were lysed in lysis buffer (1X PBS, 1\% NP40, 0.1\% sodium dodecyl sulfate, 5 mM EDTA, $0.5 \%$ sodium deoxycholate and $1 \mathrm{mM}$ sodium orthovanadate) with protease inhibitors. Subsequently, $50 \mu \mathrm{g}$ of total cellular protein from each sample were separated by $10 \%$ SDS-PAGE and electrotransferred onto a polyvinylidene fluoride (PVDF) membranes by using a semi-dry blotting apparatus (Bio-Rad). After blocking with 5\% non-fat milk, the PVDF membranes were covered with specific primary antibodies, followed by incubation with secondary antibodies. The protein bands were then visualized by using Pro-lighting HRP agent and their densities were analyzed using ImageJ software. $\beta$-actin was used as the loading control.

Animals and tumor model. Twenty BALB/c female mice, 4-5 weeks old, were purchased from the Center for New Drugs Evaluation of Shandong University, and housed under pathogen-free conditions. All the experiments were approved by the institutional guidelines of the Animal Care and Use Committee at Shandong University. 4T1 cells $\left(1 \times 10^{6}\right)$ were subcutaneously injected into the left flank of each mouse. After 2 days, each mouse was given $100 \mu$ l solution containing $50 \mathrm{mg}$ Huaier extract by gavage daily. After 21 days, the mice were sacrificed, and the xenografts were removed for immunohistochemical staining.

Histology and immunohistochemistry. Immediately after excision, the tumor tissues were stored in $10 \%$ neutral-buffered formalin. After $24 \mathrm{~h}$, the samples were paraffin-embedded and then sliced into $4-\mu \mathrm{m}$ section for hematoxylin and eosin (H\&E) staining according to the standard techniques. The relative areas of necrosis in tumors were analyzed.

To quantify the microvessel density (MVD), the SP-9000 Histostain $^{\text {TM }}$-Plus Kits (ZhongShan Goldenbridge Biotechnology Co.) were used to detect CD34 expression using the standard steps. Briefly, the sections were deparaffinized and rehydrated, followed

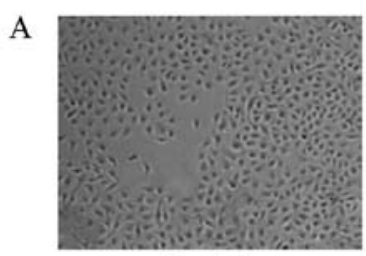

Control

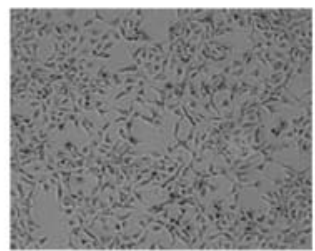

$4 \mathrm{mg} / \mathrm{ml}$

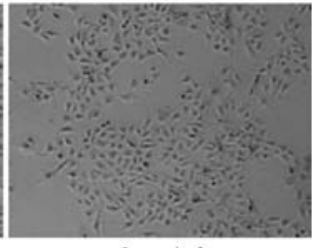

$2 \mathrm{mg} / \mathrm{ml}$

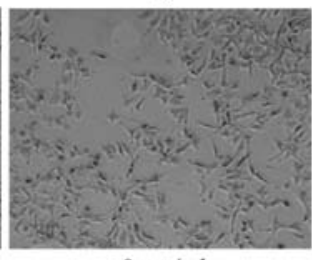

$8 \mathrm{mg} / \mathrm{ml}$
B

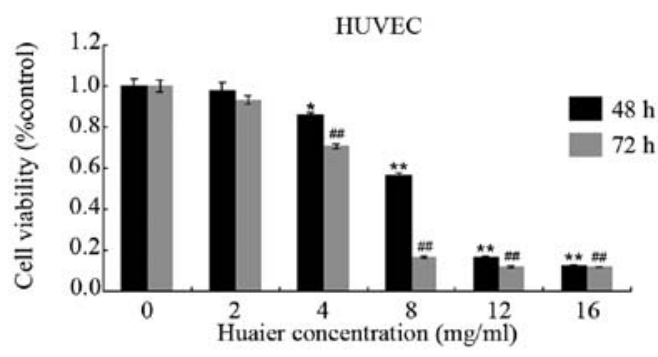

Figure 1. Morphological and viability changes in HUVECs induced by Huaier extract. (A) HUVECs were seeded in 24-well plates and incubated with Huaier extract for $24 \mathrm{~h}$. Representative images of HUVECs in the control and treated groups. (B) Huaier extract inhibited cell proliferation in a timeand dose-dependent manner. The results are presented as the means \pm SD of 3 independent experiments conducted in triplicate. ${ }^{*} \mathrm{P}<0.05 ;{ }^{* *} \mathrm{P}<0.01 ;{ }^{*} \mathrm{P}<0.05$; ${ }^{\# \#} \mathrm{P}<0.01$.

by antigen retrieval with $\mathrm{pH} 6.0$ citrate buffer. Endogenous peroxidase activity was inhibited with $3 \% \mathrm{H}_{2} \mathrm{O}_{2}$ for 15 min and the sections were incubated with $10 \%$ normal goat serum to block non-specific binding. After incubation with anti-CD34 antibody (Santa Cruz Biotechnology, Santa Cruz, CA, USA) at $4^{\circ} \mathrm{C}$ overnight, the sections were washed, treated with biotinylated anti-immunoglobulin antibody for $20 \mathrm{~min}$ and reacted with horseradish peroxidase-conjugated streptavidin. Then the liquid DAB substrate/chromogen system (Maixin Bio, Fuzhou, China) was used, followed by counterstaining with hematoxylin. The representative images of tumor tissues were taken by an Olympus light microscope.

Terminal deoxynucleotidyl transferase (TdT)-mediated dUTP nick end-labeling (TUNEL) assay. TUNEL assay was performed to identify the apoptotic cells in the paraffin-embedded sections using the One Step TUNEL Apoptosis Assay kit (Beoytime, Beijing, China) according to the manufacturer's instructions. TUNEL-positive cells were visualized with red fluorescent staining observed by a fluorescence microscope (Olympus).

Statistical analysis. The results are presented as means \pm standard deviation (SD) and differences between groups were compared by one-way ANOVA and considered significant at $\mathrm{P}<0.05$. The statistical analysis was carried out by using SSPS edition 16.0. 
A
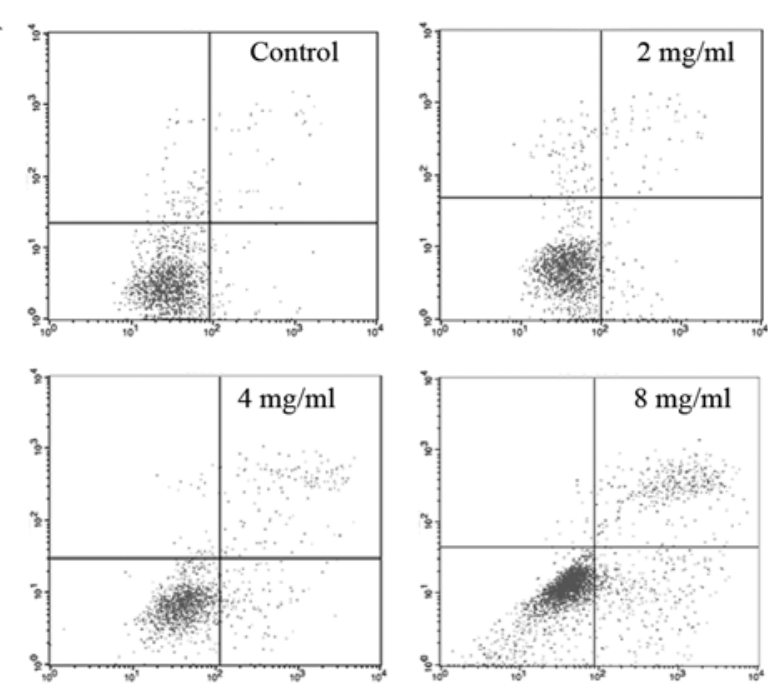

$\mathrm{C}$

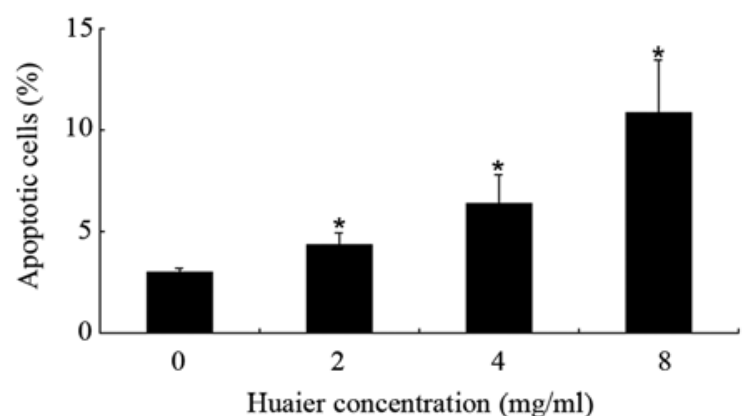

E
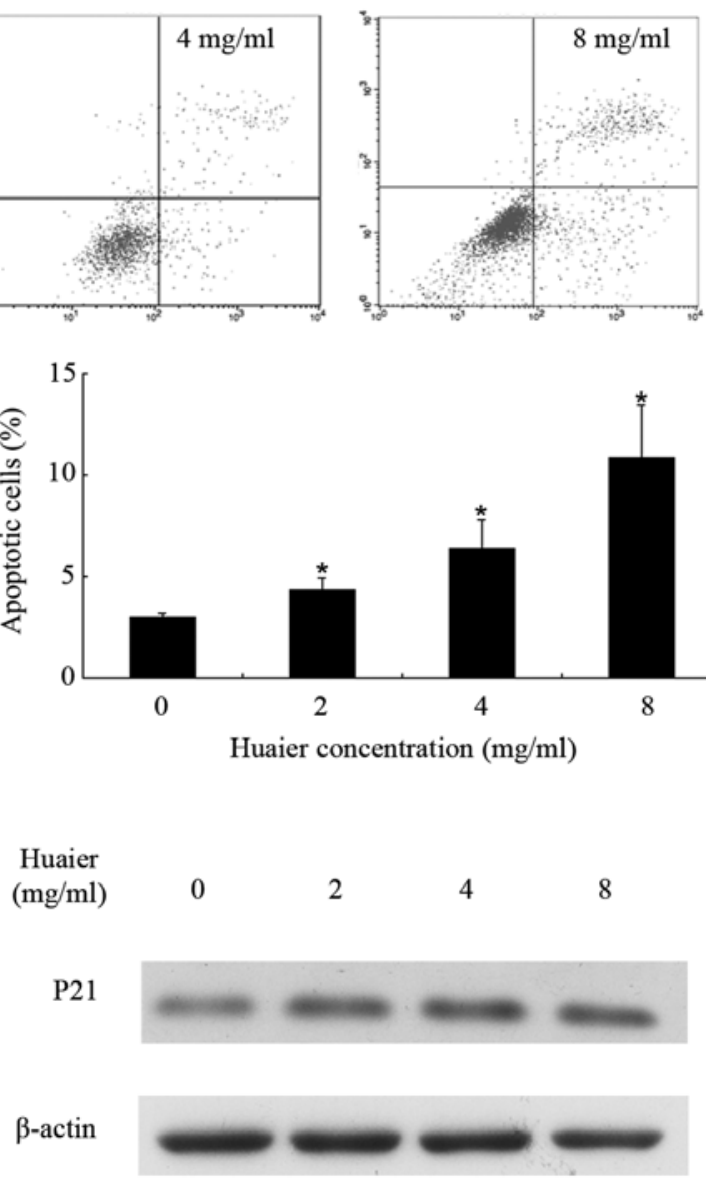

B
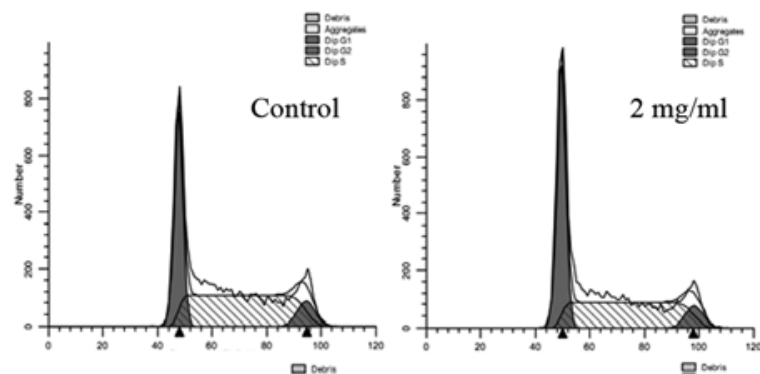

$\mathrm{D}$
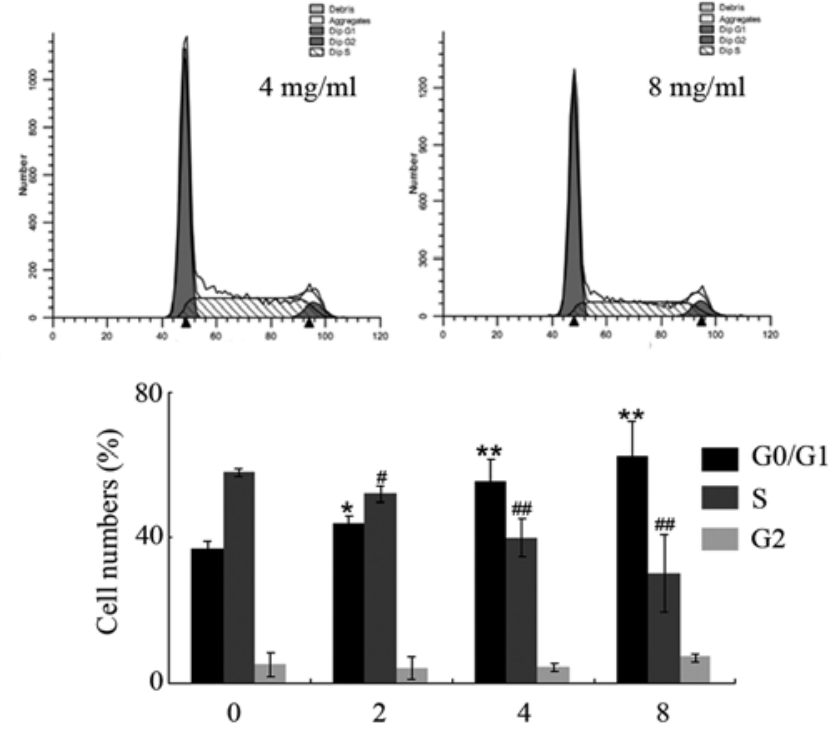

Huaier concentration $(\mathrm{mg} / \mathrm{ml})$

$\mathrm{F}$

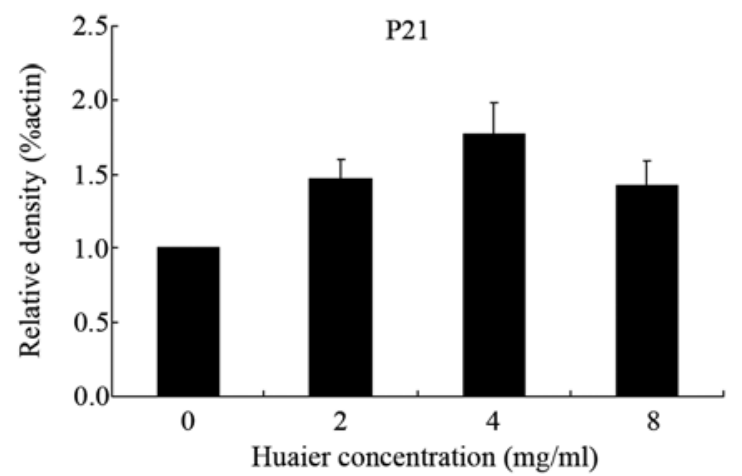

Figure 2. Huaier extract induced apoptosis and caused cell cycle arrest in HUVECs. HUVECs were incubated with increasing concentrations of Huaier extract for up to $48 \mathrm{~h}$. (A and C) Examples of flow cytometric data of HUVECs examined by PI-Annexin-V staining analysis after incubation with Huaier extract for $48 \mathrm{~h}$. (B and D) Representative images of cell cycle analysis are shown, and the percentage of cells in each phase of the cell of each following treatment for $24 \mathrm{~h}$ is presented as a histogram, and all values were expressed as the means \pm SD of 3 independent experiments conducted in triplicate. (E and F) Huaier extract induced the accumulation of $\mathrm{p} 21$. The bar graphs represent the relative density of p21/actin. Con, control. ${ }^{*} \mathrm{P}<0.05 ;{ }^{* *} \mathrm{P}<0.01 ;{ }^{*} \mathrm{P}<0.05 ;{ }^{\# \#} \mathrm{P}<0.01$.

\section{Results}

Effects of Huaier extract on cell morphology and viability of HUVECs. To investigate the effect of Huaier extract on angiogenesis, we first observed the cell morphology of the HUVECs after exposure to Huaier extract. Following $24 \mathrm{~h}$ of incubation with various concentrations of Huaier extract, the morphological changes in the HUVECs were observed (Fig. 1A). Obvious morphological changes were observed in the HUVECs. Compared with the untreated cells, the majority of the cells in the Huaier-treated groups became enlongated and star-shaped with sharp outlines. These results suggest that Huaier extract causes cell skeleton rearrangement in HUVECs.
We then examined the cell viability by using MTT assay. As shown in Fig. 1B, Huaier extract suppressed the proliferation of the HUVECs in a time- and dose-dependent manner. The inhibitory rates of Huaier extract varied from $2.3 \pm 3.7 \%$ to a maximum of $87.7 \pm 0.5 \%$ after 48 -h incubation, with an $\mathrm{IC}_{50}$ of $8.1 \pm 0.9 \mathrm{mg} / \mathrm{ml}$. After treatment with increasing concentrations of Huaier extract for $72 \mathrm{~h}$, the viabilities of the HUVECs were suppressed by $6.9 \pm 2.2,29.4 \pm 0.9,83.7 \pm 0.5,87.9 \pm 4.5$ and $88.0 \pm 0.2 \%$, respectively. A significant reduction was firstly observed at $4 \mathrm{mg} / \mathrm{ml}(\mathrm{P}<0.05)$.

Suppressive effect on HUVEC proliferation correlates with cell cycle arrest and apoptosis induction. To further explore 
A
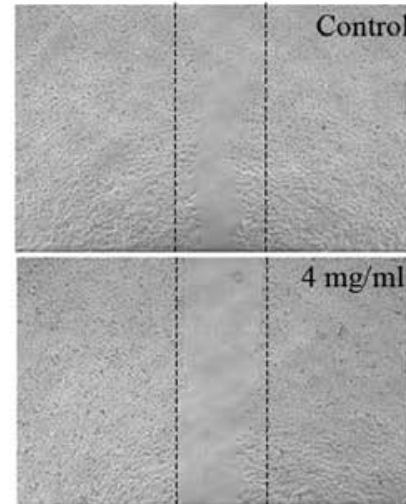

C
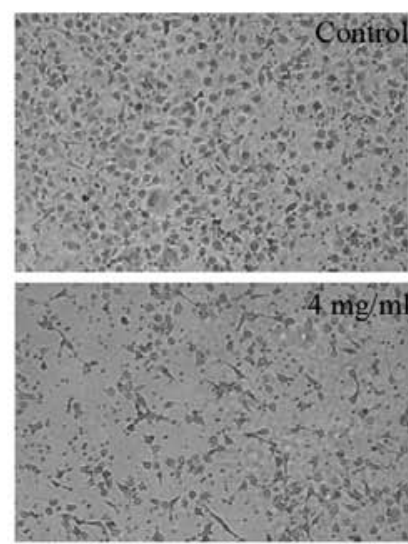

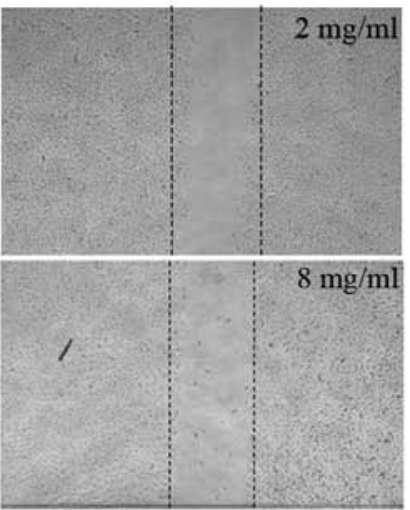

B
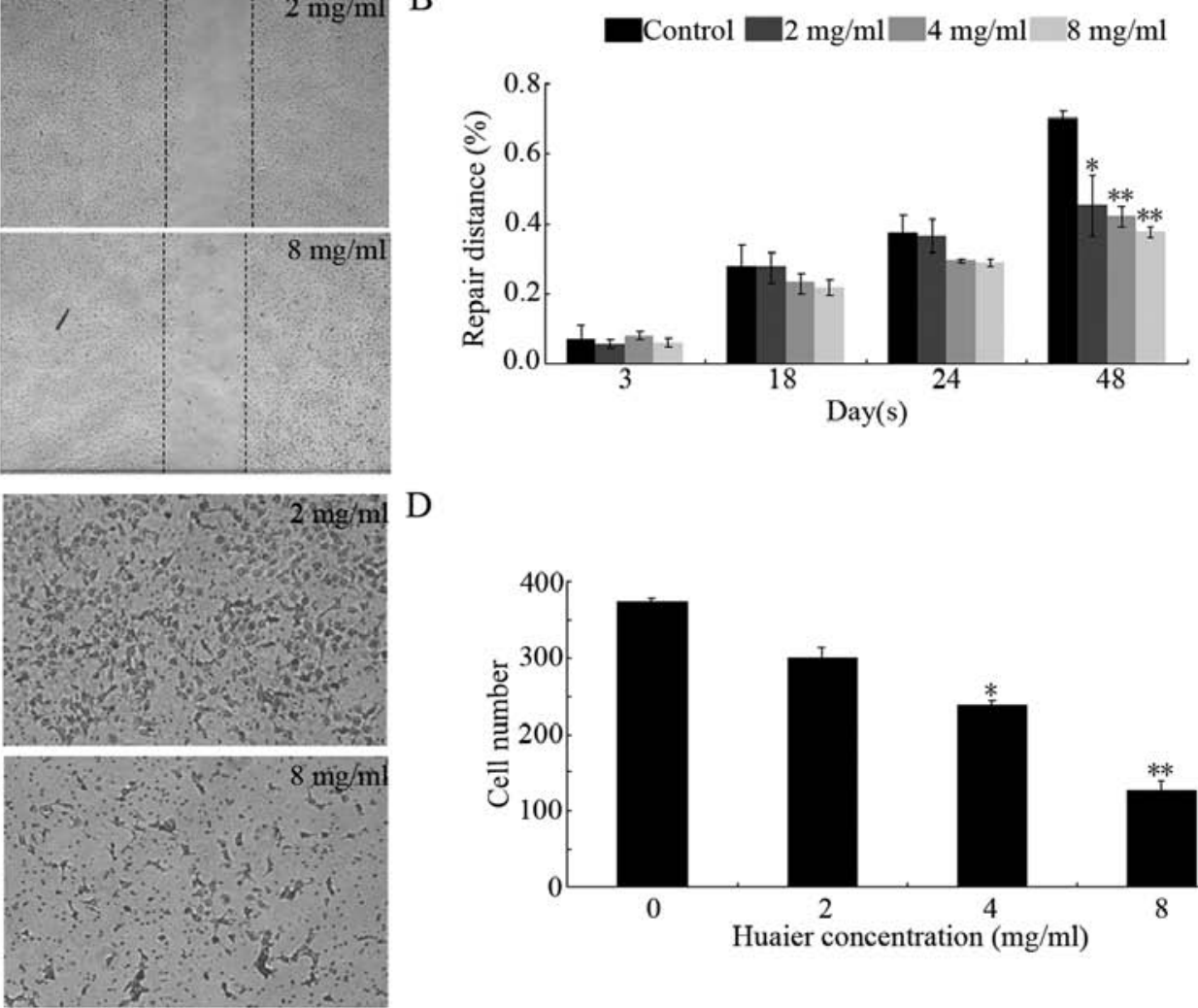

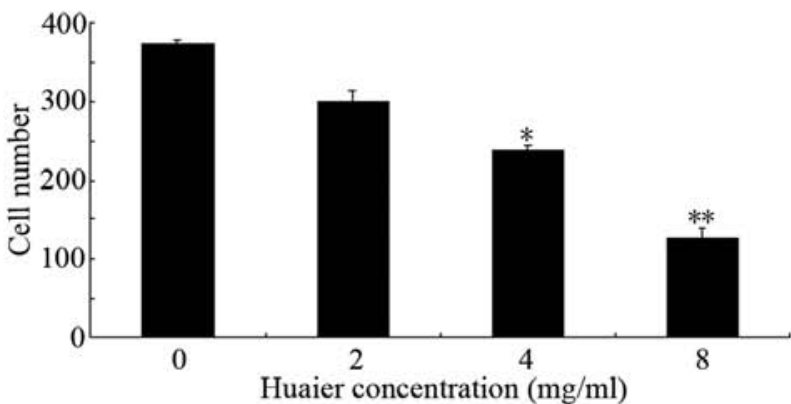

Figure 3. Effect of Huaier extract on the cell migration of HUVECs. (A) Confluent monolayers of HUVECs on a 12-well plate were wounded using a pipette tip and treated with Huaier extract or the vehicle. The images of wound closure were captured under a phase-contrast microscope after $48 \mathrm{~h}$. (B) The migration inhibition is presented as distances between the 2 edges of the scratch. (C) Chemotaxis assay of HUVECs, which shows the inhibitory effect of Huaier extract on cell migration following $24 \mathrm{~h}$ of treatment. The cells successfully migrated to the lower surface of the insert. (D) The cell numbers decreased in a dose-dependent manner following treatment with Huaier extract. In the histograms, all values are expressed as the means $\pm \mathrm{SD}$. ${ }^{*} \mathrm{P}<0.05 ;{ }^{* * *} \mathrm{P}<0.01$ as compared with the vehicle.

the underlying mechanism of the antiproliferative effect of Huaier extract, we applied flow cytometry to analyze the apoptotic rate and cell cycle distribution after treatment with Huaier extract. The data demonstrated that the ratios of apoptotic HUVECs were $4.4 \pm 0.6,6.4 \pm 1.4$ and $10.9 \pm 2.6 \%$ in the presence of increasing concentrations of Huaier extract for $48 \mathrm{~h}$, respectively (Fig. 2A and C). In addition, as shown in Fig. 2B and D, after $24 \mathrm{~h}$ of treatment, the proportion of cells at the G0/G1 phase was dose-dependently increased (from $36.79 \pm 2.25 \%$ in control group to $62.41 \pm 9.77 \%$ in $8 \mathrm{mg} / \mathrm{ml}$ Huaier group). Furthermore, treatment with Huaier extract resulted in the accumulation of p21 with a maximum at $4 \mathrm{mg} / \mathrm{ml}$ (Fig. 2E and F), and this partly contributed to the cell cycle arrest mentioned above.

Effect of Huaier extract on motility of HUVECs. We then examined the influence of Huaier extract on cell motility by using modified scratch assay (26) and cell migration assay (29). As shown in Fig. 3A and B, after treatment with Huaier extract, the migration of the HUVECs was dose- and time-dependently inhibited. This result was consistent with the results presented in Fig. 3C and D. At $8 \mathrm{mg} / \mathrm{ml}$, the number of cells which had successfully migrated to the lower side of the filter was reduced by $66.2 \pm 2.8 \%(\mathrm{P}<0.01)$ after $24 \mathrm{~h}$ of treatment with Huaier extract.
Effect of Huaier extract on angiogenesis in vitro and ex vivo. As an essential step for angiogenesis, the formation of tube-like structures involves matrix degradation, rearrangement and apoptosis of endothelial cells. As shown in Fig. 4A, untreated HUVECs formed organized capillary tubes within $9 \mathrm{~h}$. While in the presence of Huaier extract, the HUVECs rounded up and rendered incomplete network structures.

To verify the anti-angiogenic effect of Huaier extract ex vivo, CAM assay and aortic ring assay were also applied. On day 9 of embryo development, fertilized chick eggs were treated with various concentrations of Huaier extract. After $24 \mathrm{~h}$ of incubation, normal vascular pattern with numerous branchings was observed in the control group. However, Huaier extract significantly distorted the vasculature architecture on the chorioallantoic membrane in a dose-dependent manner (Fig. 4B).

The results demonstrated that Huaier extract caused a dramatic decrease in sprout length and density from the aortic ring in a dose-dependent manner (Fig. 4C). In conclusion, Huaier exhibited anti-angiogenic activity both in vitro and ex vivo.

Effect of Huaier extract on endothelial signaling pathways. To identify whether Huaier extract can regulate multiple molecules involved in angiogenesis, we used western blot analysis to investigate the changes between the vehicle- and Huaier-treated 
A

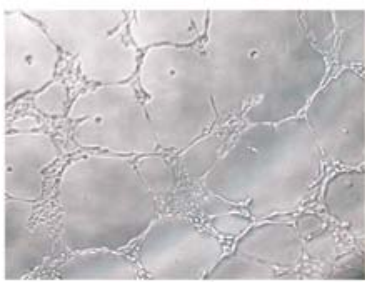

Control

B

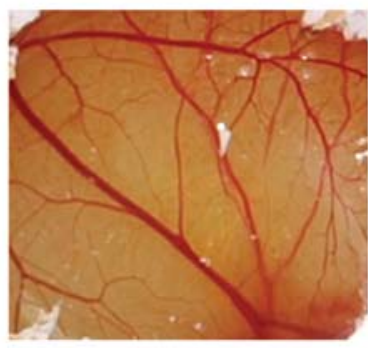

Control

$\mathrm{C}$

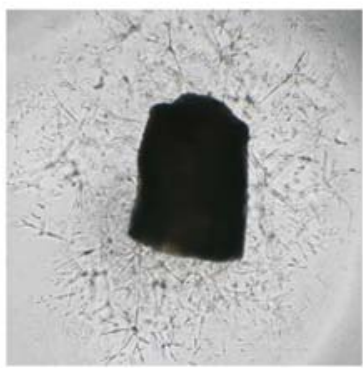

Control

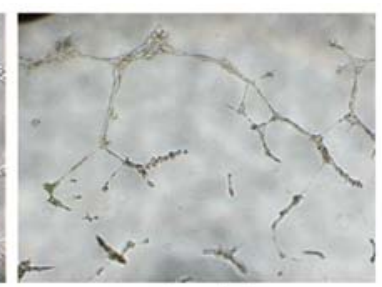

$2 \mathrm{mg} / \mathrm{ml}$

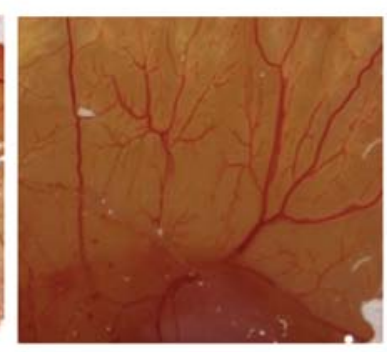

$2 \mathrm{mg} / \mathrm{ml}$

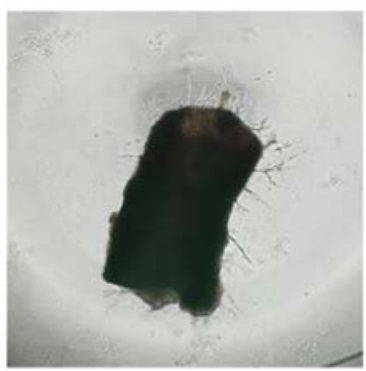

$2 \mathrm{mg} / \mathrm{ml}$

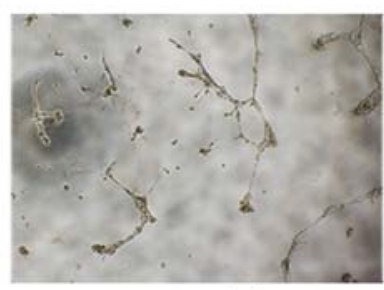

$4 \mathrm{mg} / \mathrm{ml}$

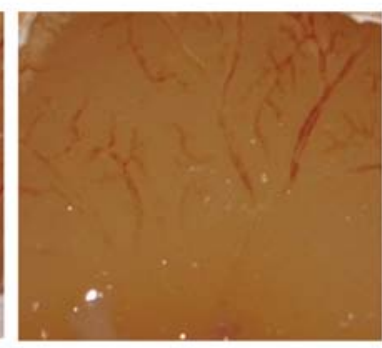

$4 \mathrm{mg} / \mathrm{ml}$

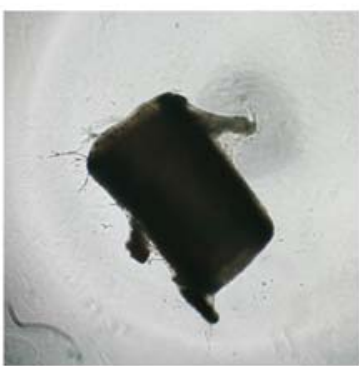

$4 \mathrm{mg} / \mathrm{ml}$

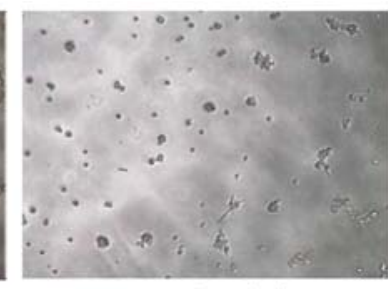

$8 \mathrm{mg} / \mathrm{ml}$

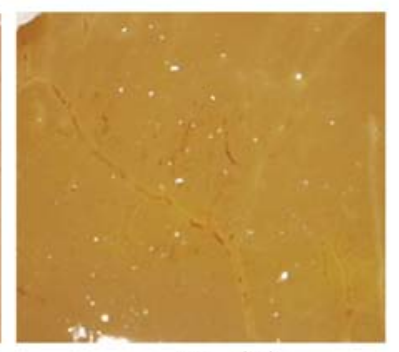

$8 \mathrm{mg} / \mathrm{ml}$

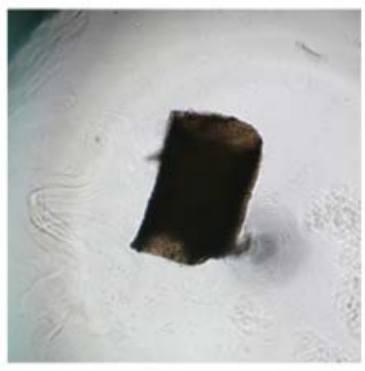

$8 \mathrm{mg} / \mathrm{ml}$

Figure 4. Huaier inhibited angiogenesis in vitro and ex vivo. (A) HUVECs were seeded on Matrigel-coated 96-well plates and incubated in the absence or presence of Huaier extract for $9 \mathrm{~h}$. Representative images of HUVEC tube formation. (B) CAM of 9-day-old chick embryos exposed to Huaier extract or the vehicle. After $24 \mathrm{~h}$ of incubation, the CAM tissue directly beneath each filter disc was photographed. The image represents at least 6 chick embryos. (C) Examples of aortic rings of mice fed with DMEM containing $20 \%$ FBS in the control and treated groups. Representative images of vessel sprouting were taken at day 5 of treatment.

A

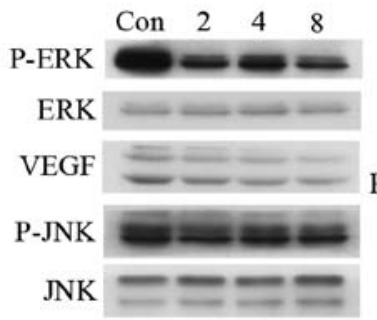

B

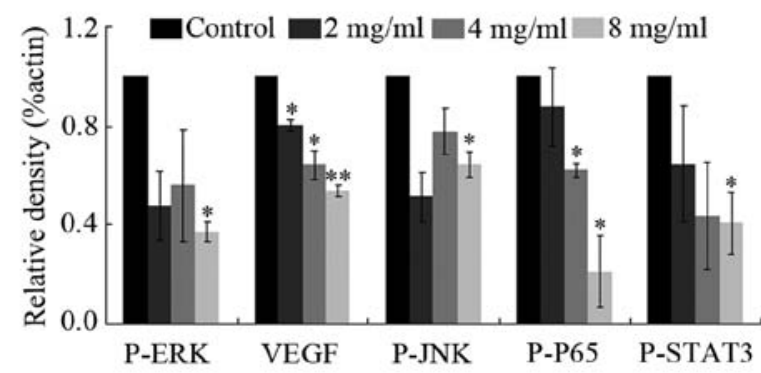

Figure 5. Huaier extract regulated multiple molecules in HUVECs. (A) After HUVECs were treated with various concentrations of Huaier extract, the expression levels of phosphorylated (P)-ERK and ERK were detected after $2 \mathrm{~h}$, while the expression of VEGF was analyzed after $24 \mathrm{~h}$ by immunoblotting. $\beta$-actin was used as the loading control. (B) The bar graphs represent the mean relative densities \pm SD of 3 independent experiments. Con, control. ${ }^{*} \mathrm{P}<0.05 ;{ }^{* *} \mathrm{P}<0.01$. groups. The results showed that Huaier extract regulated the ERK pathway by down-regulating the phosphorylation of ERK without affecting overall ERK expression levels (Fig. 5). In addition, the expression of VEGF was significantly reduced by $46.4 \pm 2.1 \%$ after incubation with $8 \mathrm{mg} / \mathrm{ml}$ Huaier extract for $24 \mathrm{~h}$ $(\mathrm{P}<0.01)$. Similarly, Huaier extract reduced the phosphorylation of JNK, STAT3 and p65. However, no effect was observed on Akt signaling and Huaier extract was unable to suppress the level of HIF (data not shown).

Huaier extract inhibits tumor growth in vitro and in a xenograft model. The antiproliferative effect of Huaier extract on 4T1 cells was examined by MTT assay. The results demonstrated that Huaier extract significantly inhibited the proliferation of $4 \mathrm{~T} 1$ cells in a time- and dose-dependent manner (Fig. 6A). With $2 \mathrm{mg} / \mathrm{ml}$ of Huaier extract, a significant suppression on $4 \mathrm{~T} 1$ cell proliferation was observed with a $7.7 \pm 0.9 \%$ (at $48 \mathrm{~h}, \mathrm{P}<0.05$ ) and $15.2 \pm 1.8 \%$ (at $72 \mathrm{~h}, \mathrm{P}<0.01$ ) reduction. The $\mathrm{IC}_{50}$ for $4 \mathrm{~T} 1$ cells was $7.9 \pm 0.9 \mathrm{mg} / \mathrm{ml}$ (at $48 \mathrm{~h}$ ) or $4.4 \pm 0.6 \mathrm{mg} / \mathrm{ml}$ (at $72 \mathrm{~h}$ ). These data suggest that 4T1 cells are more sensitive to Huaier extract than HUVECs.

Taking into account the anti-angiogenic and antitumor effects of Huaier extract in vitro and ex vivo, we then examined 
A

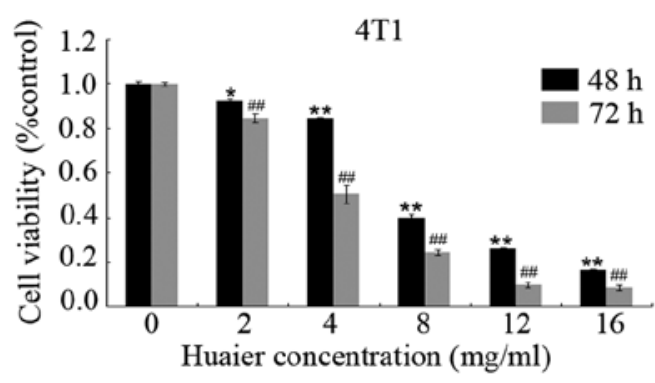

B
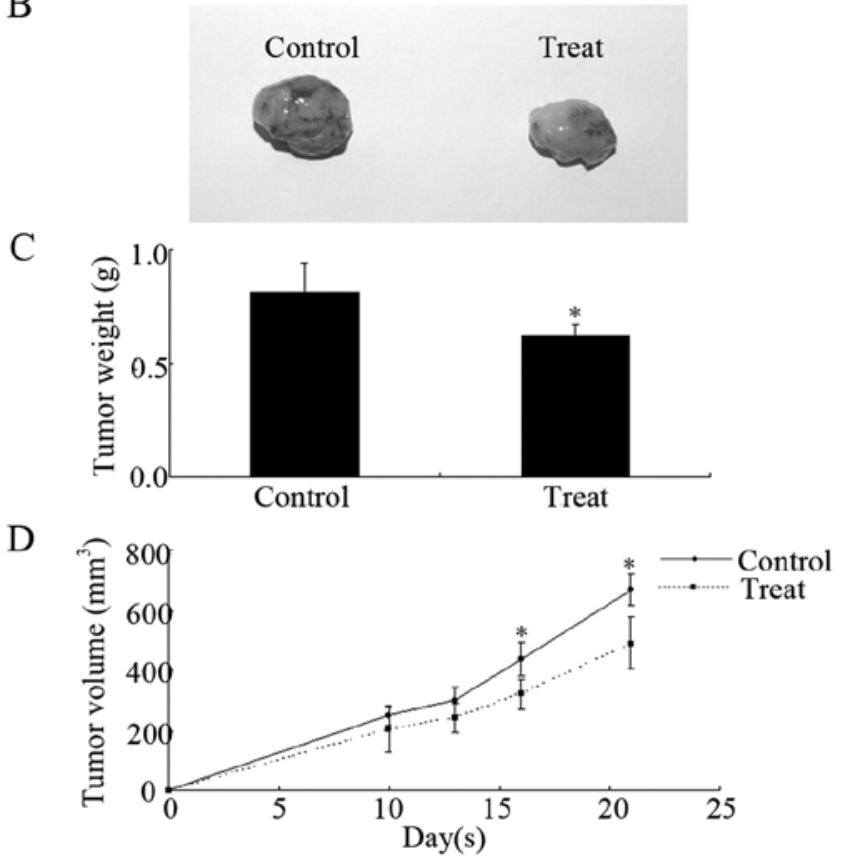

E

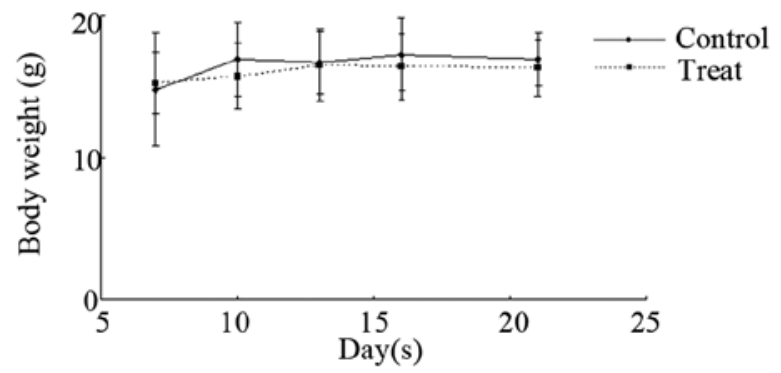

Figure 6. Huaier extract suppressed the growth of 4T1 cells in vitro and in vivo. (A) Huaier extract inhibited $4 \mathrm{~T} 1$ cell proliferation as shown by MTT assay. In the in vivo experiment, the mice were administrated with Huaier extract by gavage daily for 18 days. (B) Tumor images after mice were sacrificed. (C) Inhibition of tumor growth judging from the final tumor weight (D and E) Tumor volumes and body weights were measured 7 days later. The bars represent the means $\pm \mathrm{SD}$. ${ }^{*} \mathrm{P}<0.05 ;{ }^{* *} \mathrm{P}<0.01 ;{ }^{\#} \mathrm{P}<0.05 ;{ }^{\#} \mathrm{P}<0.01$.

the antitumor effect of Huaier extract in BALB/c mice. As shown in Fig. 6B and C, the administration of Huaier extract by gavage delayed the tumor volume at concentration of $2.5 \mathrm{~g} / \mathrm{kg}$ per day. Compared with the control group $\left(667.0 \pm 52.6 \mathrm{~mm}^{3}\right)$, tumor volumes in the Huaier-treated group were significantly smaller $\left(488.9 \pm 86.5 \mathrm{~mm}^{3}, \mathrm{P}<0.05\right)$ at day 21 . The antitumor activity of Huaier extract in vivo was confirmed by measuring the tumor weights after the mice were sacrificed. The weights of tumors isolated from the Huaier-treated groups were significantly decreased by $23.6 \pm 5.1 \%(0.81 \pm 0.13 \mathrm{~g}$ in the control
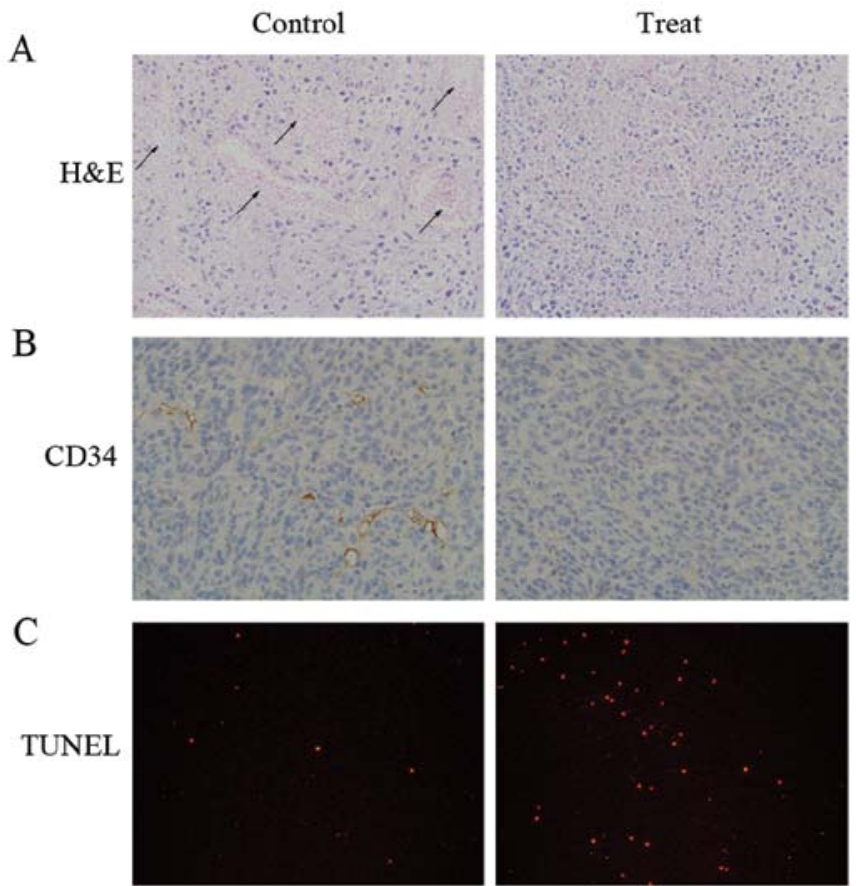

Figure 7. H\&E, CD34 and TUNEL staining of tumor tissues. 4T1 xenograft tissues were removed and cut into $4-\mu \mathrm{m}$ thick slices. Representative images of (A) H\&E staining showing the necrotic areas, (B) CD34 stainig, as an indicator of tumor microvessel density, and (C) TUNEL staining, where TUNEL-positive cells indicate apoptosis. The sites of hemorrhagic necrosis are indicated by arrows.

group, and $0.62 \pm 0.05 \mathrm{~g}$ in the treated group, $\mathrm{P}<0.05)$. However, we observed no significant difference between the 2 groups in body weight, which indicated no obvious toxicity to mice at the curative dose (Fig. 6D). Our data prove the antitumor effect of Huaier extract on 4T1 mouse mammary cancer without causing marked toxicity in vivo.

To elucidate the mechanisms behind the effect of Huaier extract in vivo, the tumor tissues from the animal models were stained with H\&E, CD34 and TUNEL (Fig. 7). The $\mathrm{H} \& \mathrm{E}$-stained sections revealed large areas of necrosis occurring in both groups. The necrotic part in the untreated tumors was hemorrhagic. However, an ischemic type of necrosis with little or no blood was observed in the Huaier-treated tumors. We then performed TUNEL staining to explore the apoptotic effect induced by Huaier extract in vivo. The increased ratio of TUNEL-positive cells clearly demonstrated that the induction of apoptosis was involved in the antitumor activity of Huaier extract. Furthermore, CD34 staining was performed to evaluate the MVD in the tumor. Under microscopic analysis, a marked decrease in the expression of CD34 was observed in the treated group compared with the control group.

\section{Discussion}

Conventional treatments for cancer patients include surgery, radiotherapy and chemotherapy. Recently, some alternative treatments, such as gene therapy and targeted therapy have attracted some attention. However, these therapies are usually unaffordable for most patients and have limited efficiency and serious side-effects. TCM has been used in China for thou- 
sands of years. Along with its anticancer effect, TCM has been widely applied to reduce toxic side-effects, improve quality of life, enhance immune function as well as prevent recurrence and metastasis for cancer patients (30). In recent years, TCM has been increasingly accepted and studied worldwide. For example, 'Chong Lou Fu Fang' was proven to improve the effect of chemotherapeutic agents on gastric cancer cells (31). Treatment with Iscador, extracted from mistletoe, resulted in a better survival among cancer patients (32). Despite of the evergrowing interest, rigorous and systematic pre-clinical evaluation is required for the globalization of TCM.

As an indispensable step for metastasis, angiogenesis is a promising target in anticancer therapy. Anti-angiogenic agents exert their effect in 2 ways $(33,34)$. Direct inhibitors disrupt the proliferation, migration and differentiation of endothelial cells. On the other hand, indirect inhibitors interfere with the communication between tumor cells and endothelial cells by suppressing the expression of pro-angiogenic cytokines or blocking the binding of factors with their receptors. Although anti-angiogenic agents exhibit obvious antitumor activities, serious side-effects are often observed following treatment, such as hypertension, impaired wound healing, haemorrhaging and thrombosis (35). Therefore, novel natural herbs, such as grape seed extract (36) and dihydroartemisinin (DHA) (37), which have been proven to be safe for humans, are recognized as sources of effective antitumor agents.

Huaier, one of the most popular medical fungi in China, belongs to the Polyporaceae family and has been used as a TCM for almost 1,600 years. In the present study, the antiangiogenic and antitumor effects of Huaier extract were assessed using HUVECs and 4T1 cells as a model. The results of MTT assay demonstrated that Huaier extract significantly attenuated the proliferation of HUVECs and 4T1 cells in a timeand dose-dependent manner $(\mathrm{P}<0.05)$. To our knowledge, this was the first study that investigated and demonstrated Huaier extract inhibited the proliferation of endothelial cells and mouse mammary tumor cells. Importantly, Huaier extract was more cytotoxic for the tumor cells with a lower $\mathrm{IC}_{50}$. In addition, the inhibition of the proliferation of HUVECs was caused by cell cycle arrest and pro-apoptotic activities. P21 is a well-studied cyclin-dependent kinase (CDK) inhibitor. It inhibits the activity of the cyclin-CDK2 or -CDK1 complex, leading to G1/S cell cycle arrest (38). After incubation with Huaier extract for $24 \mathrm{~h}$, the protein level of p21 was increased. This suggested that Huaier extract caused cell cycle arrest in the HUVECs partly by promoting p21 accumulation.

In order to reveal the potential signaling pathways underlying the potent anti-angiogenic activity of Huaier extract, we investigated the expression of some angiogenic molecules. As one of the key pro-angiogenic molecules, VEGF is a highly specific mitogen for vascular endothelial cells and a potent vascular permeability enhancer. During the process of angiogenesis, VEGF is responsible for endothelial cell proliferation, migration, and antiapoptosis (39). Certain studies have demonstrated that the overexpression of VEGF in cancer patients is associated with a poor prognosis and decreased survival (40). As shown in Fig. 5, Huaier extract inhibited the expression of VEGF in a concentration-dependent manner. Among the upstream pathways that mediate VEGF expression, PI3K/AKT and MEK/ERK play important roles (41). As shown in Fig. 5, Huaier extract dose- dependently suppressed the activation of ERK without exerting any influence on AKT. Richard et al (42), as well as a previous study (43) demonstrated that active p42/p44 MAPK increased HIF-1-dependent transcriptional activity, which finally increased the expression of downstream proteins, including VEGF. Recently, the addition of U0126, a known selective inhibitor of MAPK/ERK kinase, was shown to inhibit the tube formation and induce apoptosis in HUVECs (44). Therefore, we hypothesized that Huaier extract could suppress the activation of ERK, inhibit VEGF expression and eventually exhibit anti-angiogenic activity. In addition, JNK, STAT3 and NF- $\mathrm{BB}$ are important pathways that regulate cell migration (45-47). In this study, we provide evidence that Huaier extract inhibits the phosphorylation of JNK, STAT3 and p65 (the major component in NF- $\mathrm{kB}$ complex). These data reveal the mechanisms underlying the antiangiogenic activity of Huaier extract.

In addition to the anti-angiogenic and antitumor activities, the results from animal studies showed no significant adverse effects of Huaier extract on the body weights of the treated mice. As shown in Fig. 6E, in the treated group, gavage with $50 \mathrm{mg}$ of Huaier extract per day did not cause body weight loss compared to the control group.

In conclusion, Huaier extract is a potent anti-angiogenic and antitumor agent. A gavage dose of $2.5 \mathrm{~g} / \mathrm{kg}$ per day given to the mice was safe and effective against angiogenesis and solid tumor growth. These results highlight the possible application of Huaier extract in cancer chemoprevention and lay a solid foundation for clinical use in humans. However, further investigations are required to assess the detailed mechanisms, the responsible component(s) and to ascertain its beneficial role in the clinical setting.

\section{Acknowledgements}

This study was supported by grants from the Program for New Century Excellent Talents in the University of China and the National Natural Science Foundation of China to Professor Qifeng Yang (No. 81072150 and 81172529).

\section{References}

1. WHO: Cancer. http://www.who.int/mediacentre/factsheets/ fs297/en/index.html, 2012.

2. DeSantis C, Siegel R, Bandi P and Jemal A: Breast cancer statistics, 2011. CA Cancer J Clin 61: 409-418, 2011.

3. Jemal A, Bray F, Center MM, Ferlay J, Ward E and Forman D: Global cancer statistics. CA Cancer J Clin 61: 69-90, 2011.

4. IARC: Cancer Epidemiology Database. GLOBOCAN 2002.

5. IARC: Cancer Epidemiology Database. GLOBOCAN 2008.

6. Monsuez JJ, Charniot JC, Vignat N and Artigou JY: Cardiac sideeffects of cancer chemotherapy. Int J Cardiol 144: 3-15, 2010.

7. Bhat TA and Singh RP: Tumor angiogenesis - a potential target in cancer chemoprevention. Food Chem Toxicol 46: 1334-1345, 2008.

8. Sagar SM, Yance D and Wong R: Natural health products that inhibit angiogenesis: a potential source for investigational new agents to treat cancer - Part 1. Curr Oncol 13: 14-26, 2006.

9. Risau W: Mechanisms of angiogenesis. Nature 386: 671-674, 1997.

10. Carmeliet $P$ and Jain RK: Angiogenesis in cancer and other diseases. Nature 407: 249-257, 2000.

11. Folkman J: Angiogenesis in cancer, vascular, rheumatoid and other disease. Nat Med 1: 27-31, 1995.

12. Hanahan D and Folkman J: Patterns and emerging mechanisms of the angiogenic switch during tumorigenesis. Cell 86: 353-364, 1996. 
13. Tassi E and Wellstein A: Tumor angiogenesis: initiation and targeting - therapeutic targeting of an FGF-binding protein, an angiogenic switch molecule, and indicator of early stages of gastrointestinal adenocarcinomas. Cancer Res Treat 38: 189-197, 2006.

14. Weidner N, Carroll P, Flax J, Blumenfeld W and Folkman J: Tumor angiogenesis correlates with metastasis in invasive prostate carcinoma. Am J Pathol 143: 401-409, 1993.

15. Maeda K, Chung YS, Takatsuka S, et al: Tumor angiogenesis as a predictor of recurrence in gastric carcinoma. J Clin Oncol 13 477-481, 1995.

16. Choi HJ, Hyun MS, Jung GJ, Kim SS and Hong SH: Tumor angiogenesis as a prognostic predictor in colorectal carcinoma with special reference to mode of metastasis and recurrence. Oncology 55: 575-581, 1998.

17. Frank RE, Saclarides TJ, Leurgans S, Speziale NJ, Drab EA and Rubin DB: Tumor angiogenesis as a predictor of recurrence and survival in patients with node-negative colon cancer. Ann Surg 222: 695-699, 1995

18. Folkman J and Cotran R: Relation of vascular proliferation to tumor growth. Int Rev Exp Pathol 16: 207-248, 1976.

19. Weidner N, Semple JP, Welch WR and Folkman J: Tumor angiogenesis and metastasis - correlation in invasive breast carcinoma. N Engl J Med 324: 1-8, 1991

20. Keshavarz M, Mostafaie A, Mansouri K, Bidmeshkipour A, Motlagh HR and Parvaneh S: In vitro and ex vivo antiangiogenic activity of Salvia officinalis. Phytother Res 24: 1526-1531, 2010.

21. Lu J, Zhang K, Nam S, Anderson RA, Jove R and Wen W: Novel angiogenesis inhibitory activity in cinnamon extract blocks VEGFR2 kinase and downstream signaling. Carcinogenesis 31 481-488, 2010.

22. Nassar ZD, Aisha AF, Ahamed MB, et al: Antiangiogenic properties of Koetjapic acid, a natural triterpene isolated from Sandoricum koetjaoe Merr. Cancer Cell Int 11: 12, 2011.

23. Ren J, Zheng C, Feng G, et al: Inhibitory effect of extract of fungi of Huaier on hepatocellular carcinoma cells. J Huazhong Univ Sci Technolog Med Sci 29: 198-201, 2009.

24. Xu X, Wei Q, Wang K, et al: Anticancer effects of Huaier are associated with down-regulation of P53. Asian Pac J Cancer Prev 12: 2251-2254, 2011

25. Zhang N, Kong X, Yan S, Yuan C and Yang Q: Huaier aqueous extract inhibits proliferation of breast cancer cells by inducing apoptosis. Cancer Sci 101: 2375-2383, 2010.

26. Liang CC, Park AY and Guan JL: In vitro scratch assay: a convenient and inexpensive method for analysis of cell migration in vitro. Nat Protoc 2: 329-333, 2007.

27. Wu J, Lu Y, Gao M and Zhang W: The advances of angiogenesis assay models. Chin Pharmacol Bull 24: 11, 2008.

28. Kruger EA, Duray PH, Tsokos MG, et al: Endostatin inhibits microvessel formation in the ex vivo rat aortic ring angiogenesis assay. Biochem Biophys Res Commun 268: 183-191, 2000.

29. Patsouris D, Neels JG, Fan W, Li PP, Nguyen MT and Olefsky JM: Glucocorticoids and thiazolidinediones interfere with adipocytemediated macrophage chemotaxis and recruitment. J Biol Chem 284: 31223-31235, 2009.

30. Hu B, Du Q, Shen K and Xu L: Principles and scientific basis of traditional Chinese medicine in cancer treatment. J Bioanal Biomed S 6: 2, 2012.

31. Liu Y, Ling Y, Hu W, et al: The herb medicine formula 'Chong Lou Fu Fang' increases the cytotoxicity of chemotherapeutic agents and down-regulates the expression of chemotherapeutic agent resistance-related genes in human gastric cancer cells in vitro. Evid Based Complement Alternat Med 2011: 834231 2011.
32. Ostermann T, Raak C and Bussing A: Survival of cancer patients treated with mistletoe extract (Iscador): a systematic literature review. BMC Cancer 9: 451, 2009.

33. Abdollahi A, Lipson KE, Sckell A, et al: Combined therapy with direct and indirect angiogenesis inhibition results in enhanced antiangiogenic and antitumor effects. Cancer Res 63: 8890-8898, 2003.

34. Folkman J, Hahnfeldt P and Hlatky L: The logic of anti-angiogenic gene therapy. Cold Spring Harbor Monograph Archive 36: 527-543, 1999.

35. Kamba T and McDonald DM: Mechanisms of adverse effects of anti-VEGF therapy for cancer. Br J Cancer 96: 1788-1795, 2007.

36. Wen W, Lu J, Zhang K and Chen S: Grape seed extract inhibits angiogenesis via suppression of the vascular endothelial growth factor receptor signaling pathway. Cancer Prev Res 1: 554-561, 2008.

37. Wang SJ, Sun B, Cheng ZX, et al: Dihydroartemisinin inhibits angiogenesis in pancreatic cancer by targeting the NF-kappaB pathway. Cancer Chemother Pharmacol 68: 1421-1430, 2011.

38. Brugarolas J, Moberg K, Boyd SD, Taya Y, Jacks T and Lees JA: Inhibition of cyclin-dependent kinase 2 by p21 is necessary for retinoblastoma protein-mediated G1 arrest after $\gamma$-irradiation. Proc Natl Acad Sci USA 96: 1002-1007, 1999.

39. Neufeld G, Cohen T, Gengrinovitch S and Poltorak Z: Vascular endothelial growth factor (VEGF) and its receptors. FASEB J 13: 9-22, 1999.

40. Paley PJ, Staskus KA, Gebhard K, et al: Vascular endothelial growth factor expression in early stage ovarian carcinoma. Cancer 80: 98-106, 1997.

41. Yang XM, Wang YS, Zhang J, et al: Role of PI3K/Akt and MEK/ ERK in mediating hypoxia-induced expression of HIF-1alpha and VEGF in laser-induced rat choroidal neovascularization. Invest Ophthalmol Vis Sci 50: 1873-1879, 2009.

42. Richard DE, Berra E, Gothie E, Roux D and Pouyssegur J: p42/p44 mitogen-activated protein kinases phosphorylate hypoxia-inducible factor 1alpha (HIF-1alpha) and enhance the transcriptional activity of HIF-1. J Biol Chem 274: 32631-32637, 1999.

43. Wang FS, Wang CJ, Chen YJ, et al: Ras induction of superoxide activates ERK-dependent angiogenic transcription factor HIF-1alpha and VEGF-A expression in shock wave-stimulated osteoblasts. J Biol Chem 279: 10331-10337, 2004.

44. Kunimasa K, Ahn MR, Kobayashi T, et al: Brazilian propolis suppresses angiogenesis by inducing apoptosis in tube-forming endothelial cells through inactivation of survival signal ERK1/2. Evid Based Complement Alternat Med 2011: 870753, 2011.

45. Huang C, Rajfur Z, Borchers C, Schaller MD and Jacobson K: JNK phosphorylates paxillin and regulates cell migration. Nature 424: 219-223, 2003

46. Yahata Y, Shirakata Y, Tokumaru S, et al: Nuclear translocation of phosphorylated STAT3 is essential for vascular endothelial growth factor-induced human dermal microvascular endothelial cell migration and tube formation. J Biol Chem 278: 40026-40031, 2003.

47. Collins T, Read MA, Neish AS, Whitley MZ, Thanos D and Maniatis T: Transcriptional regulation of endothelial cell adhesion molecules: NF-kappa B and cytokine-inducible enhancers. FASEB J 9: 899-909, 1995. 